\title{
Stress and Well-Being among First year and Last year college students during COVID-19
}

\author{
Kavya Ahuja ${ }^{1}$, Megha Garg ${ }^{1}$ \\ ${ }^{1}$ M.Sc. Clinical Psychology, Amity University, Haryana \\ Corresponding author: Megha Garg \\ Email-gargmegha1501@gmail.com
}

\begin{abstract}
Background: The closure of educational institutions due to COVID-19 pandemic is causing a varied amount of distress among students depending on their year of study. The purpose of the study was to compare first year and Last year College going students on the variables stress and well-being.

Methodology: A population of 50 first year and 50 last year students participated in the study and were recruited from different colleges of Delhi and Gurgaon. The participants completed a measure of Perceived stress scale and P.G.I. general well-being measure Questionnaire.

Results: The results reveal that there is significant difference in both variable i.e stress and well-being among first year and Last Year College going students based on the analysis of data done by using Independent sample t-test.

Conclusions: Interventions to boost Mental Health of the final year students by increasing support and providing assurance in both, academic and employment opportunities will be helpful during these times.
\end{abstract}

Keywords: Stress, Well Being, College going students, COVID-19.

(Paper received $-1^{\text {st }}$ December 2020, Peer review completed $-5^{\text {th }}$ January 2021)

(Accepted $-8^{\text {th }}$ January 2021)

\section{INTRODUCTION}

The end of 2019 saw an outbreak of a deadly disease COVID-19 which has found its way into the entire world and is swiftly spreading its claws onto the well-being of people. It has been declared to be a pandemic and has claimed lives across the globe. While physicians are calling it to be a physical health pandemic, mental health experts are of the opinion that this is taking a toll on people's mental well-being as well. Taking in view its transmission rate and acting on the advice of World Health Organization, the countries have imposed a lockdown, confining people inside their homes. This has triggered an un-certainty for people all over, irrespective of their gender, class, age, etc. Students especially are facing a lot of stress as they are unsure of what lays ahead and if they'll ever be able to write their exams. While we have students studying in different years, their stress and anxiety levels vary according to their year of study. A student from 1st year who was supposed to enter his 2 nd year of college might find himself in a better position than someone who was in his final year of college, looking forward to get placed or seek admission in higher education. Therefore, this paper aims to assess the difference between the levels of perceived stress and well-being between these two groups of students belonging to first year and final of college [1-3].

\section{Perceived Stress}

Where stress is the pressure faced by an individual due to prevailing conditions, perceived stress refers to the perception held by an individual about his level of stress. Perceived stress refers to how he feels about his stress levels. It does not measure the frequency of feeling stressful but the feelings of an individual related to it. Perceived stress measures the beliefs of an individual about his ability to handle stress and his 
environment. It is likely that when faced with a similar negative event twice, an individual's level perceived stress is different in both the cases. This difference can be attributed to a person's personality, availability of resources and support. Keeping these things in mind, it can be said that perceived stress is a reflection of interaction between a person with his environment which they perceive as threatening or over-exploiting their resources affecting their well-being. It is depicted by the frequency of such thoughts or feelings [4-5].

\section{General well being}

According to Davis [6], Well-being is a feeling of happiness, health and prosperity. A person with high wellbeing, has a higher life satisfaction, his mental health is in good shape he is able to manage stress effectively and has a sense of purpose or meaning. Due to its positive factors, such as heeling of being healthy, happy, purposeful and socially connected with their environment, everyone seeks for well-being in their lives.

According to Masters [7], general well-being has multiple aspects or facets, which are:

- Mental well-being: Sawyer [8] found that $14 \%$ of Australian children and adolescents display some or the other kind of mental health problems.

- Emotional well-being: McMillan and Hillman [9], in their study among youth identified that the young people who were unemployed or were not in the labour force had significantly lower level of wellbeing.

- Spiritual well-being: According to Hill [10], self-harm can be a result from disintegration- against abuse, neglect, or despair- of a person's framework of meaning.

- Physical well-being: Rowe, Rowe and Pollard [11], found an association between externalizing behaviour problems and some type of physical problems among school children.

- Social well-being: Wright and Cropanzano [12], concluded in their study among MBA students that people with higher social wellbeing are superior in decision making, demonstrated better interpersonal behaviours, and had higher overall ratings in performance.

These discipline although different, are not independent of each other and are correlated among themselves. Any variation in one of these aspects will automatically affect the others. Well-being in student life has been the main focus of educators since it would set a course for the development of the future of the nation. Students with higher well-being, are more likely to thrive in their higher education. In a study done by Strizhistskaya [13], which examined the association among perceived stress, emotional stability and psychological well-being among 323 adults ranging from 20-60 years of age, it was found that these three variables were correlated with each other. It was also found that emotional stability can moderate the relationship between perceived stress and psychological well-being. Another study done by Anushri and others [14] which examined the relationship between perception of stress and psychological well-being among a sample of dental students of under graduation in Bangaluru, concluded that gender and health behaviours which indirectly affect psychological general well-being influences the perception of stress. The aim of this study was to compare the first year students and last year students on the variables stress and well-being during the COVID-19 pandemic.

\section{METHODOLOGY}

Hypothesis: In the present paper it is hypothesized that -

H1- First Year College going students shows significantly lower stress than Last Year College going students.

H2- First Year College going students shows significantly lower well-being than Last Year College going students.

\section{Research design}

The investigation of the present research is based on non-experimental cross-sectional research design. The study is an empirical type study which is quantitative in nature. 


\section{Sample}

Participants consists of 100 (50 First Year students and 50 Last Year Students). Ranging from 18-25 years of age. Participants were recruited from different colleges of Delhi and Gurgaon through Purposive Sampling technique.

\section{Selection Criteria for caretakers}

Inclusion Criteria: College students, first year and last year students.

Exclusion criteria: School going students, second year college going students

\section{Tools:}

The following two tools were used in this study:

P.G.I General well-being measure: PGI General well-being measure was developed by Santosh K.Verma and Amita Verma [15]. It consists of 20 items to be enclosed in yes or no format. A score of 1 is given for yes and zero is given for no response. Number of ticks was counted and that constituted the wellness of that particular individual at that time. Subjects who acquired more than 10 points on this scale had been viewed healthy. The reliability estimated by Kuder and Richardson formula 20 was 0.98 (P 0.01) and for test retest reliability the coefficient was 0.91 (P 0.01) [15].

Perceived stress scale (PSS-10): Perceived Stress Scale was developed by Cohen Williamson in 1988. It consists of 10 items implied to evaluate how unpredictable, uncontrollable, and overloaded respondents find their lives. Subject rate the item on 5- point Likert scale, ranging from 0 (never) to 4 (very often). Items 4, 5, 7 and 8 are reversely scored and items are summed to obtain the final score. Total scores range from 0 to 40 , with higher scores indicating higher levels of perceived stress. The reliability estimated by Cronbach's alpha was $0.842[16]$.

\section{Procedure}

The questionnaires were converted into a Google Forms. The respondents were approached personally, the purpose of the research was explained and after taking their consent for being assessed, then respondents were provided with the instructions regarding how to answer each tool and were requested to give honest responses assuring that their identity would be kept confidential and information provided by them would be used exclusively for the purpose of research work. The tools were answered by all the respondents.

\section{Ethical considerations}

The researcher personally approached each participant to explain the study and requested his or her participation. All participants were informed that participation in the study was voluntary and they were free to withdraw. Participants had the opportunity to ask questions regarding their participation and had additional opportunities to ask questions during the time of filling form.

\section{STATISTICAL ANALYSIS}

For the purpose of data analysis the present study has used descriptive statistical techniques to find out mean, standard deviation. To compare the two groups Independent sample t-test has been applied.

\section{RESULTS}

The purpose of this study was to compare First Year College Student and Last year College student pertaining to their Stress and well-being and in doing so the following tools have been used: P.G.I General well-being measure and Perceived Stress Scale. According to table 1, the mean difference for Stress of First Year College Students came out to be 18.54 while the same for Last Year college students came out to be 23.12. The standard deviation for Stress of the First year Student came out to be 5.39 while the same for Last Year students came out to be 5.09. The standard error of mean for Stress of First Year College Students came out to be 0.76 while the same for Last Year Students came out to be 0.72 . The standard error of 
difference for Stress came out to be 1.049. The t-value is 4.3663 (Table1) which means findings are extremely statistically significant so the hypothesis that First Year College going student Shows Lower Stress than Last Year College Going students has been supported.

Table 1: Descriptive statistics of First Year College Students and Last Year College Students

\begin{tabular}{|c|c|c|c|c|c|c|c|}
\hline Variables & Group & Mean & $\begin{array}{c}\text { Standard } \\
\text { deviation }\end{array}$ & $\begin{array}{c}\text { Std. error of } \\
\text { mean }\end{array}$ & $\begin{array}{c}\text { Std. error of } \\
\text { difference }\end{array}$ & T & P value \\
\hline \multirow{2}{*}{ Stress } & First Year & 18.54 & 5.39 & 0.76 & 1.049 & 4.3663 & $<0.0001$ \\
\cline { 2 - 5 } & Last Year & 23.12 & 5.09 & 0.72 & & & \\
\hline \multirow{2}{*}{ Well being } & First Year & 13.52 & 4.63 & 0.65 & 0.957 & 2.2790 & 0.0248 \\
\cline { 2 - 5 } & Last Year & 11.34 & 4.93 & 0.70 & & & \\
\hline
\end{tabular}

The mean difference for well-being of First Year College going Students came out to be 13.52 while the same for last year College going students came out to be 11.34. The standard deviation for well-being of the First Year College Students came out to be 4.63 while the same for Last year College Going Students came out to be 4.93. The standard error of mean for well-being of the First Year College Students came out to be 0.65 while the same for Last Year College going students came out to be 0.70 . The standard error of difference for well-being came out to be 0.957 . The t-value is 2.2790 (Table1) which means findings are statistically significant so the hypothesis that First year college going students shows significantly lower well-being than Last year college going students has been supported.

\section{DISCUSSION}

COVID-19 pandemic has brought a lot of uncertainties in the lives of people of all ages and disciplines. Despite various efforts, people are finding it hard to retain their jobs and are facing the wrath of their employers for even minor mistakes. Among students, the closure of educational institutions has become a matter of great concern as it has disrupted their learning process. Even though the classes have shifted online, students face a lot of difficulties in accessing them due to a variety of reasons urging the institutions to struggle to provide quality education. Along with hindrances classes, it has also created a question of assessment procedures in the colleges. With most colleges planning their exams in the months of April-May, this lockdown has made it impossible for students and staff members to conduct the examinations physically in exam centres or classrooms, jeopardizing the future of students, especially those who were in their last year, looking ahead for enrolling in higher studies or getting a job. Perceived Stress was found to be higher in Last year students owing to the uncertainty that their future holds in terms of either getting a job or in higher studies, the entire process is now on hold, decreasing their foresight into their future. Mental health of such students is of big concern to educators and researchers, since they are likely to be heavily affected by this pandemic mentally and emotionally. This also accounts for the significant low levels of General wellbeing among them as compared to those in their First year of college. On the other hand, students who are in their first year have comparatively more time to cope with this loss and are less likely to experience grave levels of problem in mental health due to the change in their mode of education. Therefore, this paper examined the difference in two aspects, namely, Perceived stress and General well-being of mental health of these two categories of students and the results clearly show a presence of significant difference between the two groups on these variables.

\section{CONCLUSION}

Students are the building blocks of any society. They are the future of our nation therefore, it is necessary to look after their well-being, especially during these unprecedented times. Despite a few limitations this paper was able to establish some important things such as academically, last year students experience higher levels of perceived stress and lower levels of general well-being as compared to the students in first year students. 
The findings of this paper can have important implications and can be employed by educators to look after the mental health of students and assist them during these dire situations.

\section{Limitations and Recommendations}

Just like any other research, the present study also has some limitations. The sample size was small, the researcher could not focus on any one city and the sample was divided into two cities, Delhi and Gurugram. Despite these limitations, there is still scope to conduct further researches in this field where the researcher can collect a large sample size and focus on only one city.

\section{REFERENCES}

1. Aristovnik A, Keržič D, Ravšelj D, Tomaževič N, Umek L. Impacts of the COVID-19 pandemic on life of higher education students: A global perspective. Sustainability 2020;12(20):8438.

2. Gonzalez T, De La Rubia MA, Hincz KP, Comas-Lopez M, Subirats L, Fort S, Sacha GM. Influence of COVID-19 confinement on students' performance in higher education. PloS One 2020;15(10):e0239490.

3. Daniel J. Education and the COVID-19 pandemic. Prospects 2020;49(1):91-6.

4. Phillips AC. Perceived stress. In M. Gellman, \& J. R. Turner, Encyclopedia of Behavioral Medicine (pp. 14531454). New York: Springer; 2013.

5. Lazarus RS, Folkman S. Stress, coping and adaptation. New York: Springer; 1984.

6. Davis, T. What Is Well-Being? Definition, Types, and Well-Being Skills. Retrieved from Psychology Today: https://www.psychologytoday.com/us/blog/click-here-happiness/201901/what-is-well-being-definitiontypes-and-well-being-skills; 2019.

7. Masters GN. Conceptualising and Researching Student Wellbeing: 2004. https://research.acer.edu.au/research conference 2004/1.

8. Sawyer M. The Mental Health and Wellbeing of Young People in Australia. Paper presented at Research Conference 2004: Supporting Student Wellbeing. Adelaide, SA: ACER; 2004.

9. McMillan J, Hillman K. The Emotional Wellbeing of Young People - School, Further Study, Work and Beyond. Paper presented at Research Conference 2004: Supporting Student Wellbeing. Adelaide, SA: ACER; 2004.

10. Hill BV. Core Values in Practice. Paper presented at Research Conference 2004: Supporting Student Wellbeing. Adelaide, SA: ACER; 2004.

11. Rowe K, Pollard J. Literacy, Behaviour and Auditory Processing - building fences at the top of the cliff in preference to ambulance services at the bottom. Paper presented at Research Conference 2004: Supporting Student Wellbeing. Adelaide, SA: ACER; 2004.

12. Wright TA, Cropanzano R. The role of psychological well-being in job per-formance: A fresh look at an ageold quest. Organiz Dynamics 2004;33:338-51.

13. Strizhitskaya O. Perceived Stress and Psychological Well-Being: The Role Of The Emotional Stability. Eur Proc Soc Behav Sci 2019;2:155-62.

14. Anushri M, Yashoda R, Puranik MP. Relationship between psychological well being and perceptions of stress among undergraduate dental students in Bengaluru city: A cross-sectional study. J Indian Assoc Pub Health Dentist 2018;12(4):283-92.

15. Verma SK, Verma A. PGI General Wellbeing Measure. Lucknow: Ankur Psychological Agency; 1989.

16. Cohen S, Kamarck T, Mermelstein R. A global measure of perceived stress. J Health Soc Beehav 1983;4:38596.

$$
\begin{gathered}
\text { Acknowledgements - Nil } \\
\text { Conflict of Interest - Nil } \\
\text { Funding - Nil }
\end{gathered}
$$

